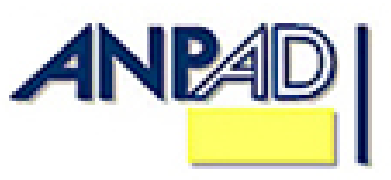

Disponível em

http://www.anpad.org.br/rac

RAC, Curitiba, v. 15, n. 1, art. 3, pp. 47-66, Jan./Fev. 2011

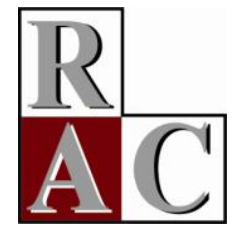

\title{
Redes Sociais na Produção Científica dos Programas de Pós- Graduação de Ciências Contábeis do Brasil
}

\section{Social Networks in the Scientific Production of Postgraduate Programs of Accounting Sciences in Brazil}

Sabrina do Nascimento * E-mail: sabnascimento@gmail.com Universidade Regional de Blumenau - PPGCC/FURB Blumenau, SC, Brasil.

Ilse Maria Beuren

E-mail: ilse@ furb.br Universidade Regional de Blumenau - PPGCC/FURB Blumenau, SC, Brasil.

* Endereço: Sabrina do Nascimento

Rua Antonio da Veiga, 140, Sala D 202, Bairro Victor Konder, Blumenau/SC, 89012-900.

Copyright (C) 2011 RAC. Todos os direitos, até mesmo de tradução, são reservados. É permitido citar parte de artigos sem autorização prévia, desde que seja identificada a fonte. 


\title{
Resumo
}

Este estudo objetiva identificar a formação de redes sociais na produção científica definitiva do triênio 2007 2009 dos programas de pós-graduação de ciências contábeis do Brasil. Pesquisa descritiva, por meio de um estudo bibliométrico e sociométrico, foi realizado, considerando os 199 docentes permanentes de 21 cursos de mestrado e doutorado dos programas de pós-graduação em ciências contábeis, distribuídos em 17 instituições de ensino superior. $\mathrm{Na}$ análise dos dados utilizou-se estatística descritiva, com auxílio do software UNICET® 6 para confecção das redes de cooperação entre os programas investigados. Os resultados da pesquisa mostram que a evolução da produção científica definitiva, no triênio 2007-2009, em termos percentuais, foi maior nos programas com conceito 3; que a produção científica definitiva veiculada em periódicos pelos docentes permanentes dos programas analisados apresenta-se de forma dispersa nas estratificações do Qualis CAPES; e que a centralidade da rede social é ocupada pelo programa da USP. Conclui-se que, de modo geral, os programas de pós-graduação em ciências contábeis apresentam ligações fracas, esparsas e pouco densas.

Palavras-chave: programas de pós-graduação em ciências contábeis; redes sociais; produção científica.

\begin{abstract}
This study aims to identify the development of social networks in the final scientific production of the 2007 2009 triennial of post graduate programs in accounting sciences in Brazil. A descriptive research, done through a bibliometric and sociometric study, was conducted, considering the 199 permanent faculties of 21 master and doctoral postgraduate programs in accounting sciences, distributed in 17 institutions of higher education. In the data analysis, descriptive statistics were used, with the aid of UNICET $₫ 6$ software to create cooperation networks between the programs under study. The results show that the evolution of final scientific production in the 2007-2009 triennial was, in percentage terms, higher in grade 3 programs; the final scientific production published in journals by the programs' faculty analyzed is scattered throughout Qualis CAPES stratifications; and that the centrality of the social network is taken by the USP program. It was concluded that, in general, the postgraduate programs of accounting sciences have weak, scattered and sparse links.
\end{abstract}

Key words: postgraduate programs in accounting sciences; social networks; scientific production. 


\section{Introdução}

A evolução das ciências contábeis no Brasil foi impulsionada pela criação de cursos de graduação e o surgimento de cursos de pós-graduação lato e stricto sensu. O primeiro programa de pós-graduação com um curso de mestrado e doutorado na área de Contabilidade foi instalado em 1977 em São Paulo, ofertado pela Universidade de São Paulo. Embora este programa de pós-graduação já exista há mais de 30 anos, somente desde 2005 houve uma elevação na taxa de crescimento dos programas na área de ciências contábeis (Cunha, Martins, \& Cornachione, 2008). De acordo com a Coordenação de Aperfeiçoamento de Pessoal de Nível Superior (CAPES, 2010), atualmente existem 24 cursos de pós-graduação stricto sensu em ciências contábeis, sendo 20 cursos de mestrado e quatro de doutorado.

Os programas de pós-graduação em ciências contábeis contribuem para a evolução da Contabilidade por meio de pesquisas científicas na área, além de incentivarem a construção e a disseminação do conhecimento. Neste contexto destaca-se a relevância da formação de redes sociais entre os pesquisadores destes programas. De acordo com Balestrin, Verschoore e Reyes (2010), no contexto acadêmico o estudo destas redes sociais tem evoluído substancialmente nas últimas décadas. Silva, Matheus, Parreiras e Parreiras (2006) afirmam que este crescimento é decorrente do aumento de dados disponíveis para análise, aumento do poder computacional para utilização dos pesquisadores, bem como a ampliação de áreas de conhecimento que utilizam as redes sociais como ferramenta de análise. As redes sociais são ligações oriundas da rede de relacionamentos estabelecidas pelos atores sociais no ambiente em que estão insertos, por meio delas é possível fortalecer e consolidar as ideias, atividades de pesquisa e de produção científica conjunta na figura das coautorias.

Assim emerge a indagação que norteia esta pesquisa: Quais as redes sociais formadas a partir da produção científica definitiva dos programas de pós-graduação em ciências contábeis no Brasil? O objetivo do estudo é identificar a formação de redes sociais na produção científica definitiva do triênio 2007-2009 dos programas de pós-graduação de ciências contábeis do Brasil. Para alcançar o objetivo proposto, buscou-se identificar a evolução da produção científica definitiva dos programas analisados; examinar a veiculação da produção científica dos programas nos periódicos classificados pelo Qualis CAPES no triênio 2007-2009; e analisar a formação das redes sociais pelos programas de pósgraduação em ciências contábeis do Brasil.

Este estudo insere-se no contexto das pesquisas que visam entender as redes sociais no âmbito da produção científica, tencionando quantificar a troca de informações e a construção do conhecimento científico no âmbito das ciências sociais aplicadas. Em âmbito nacional destacam-se os estudos realizados por Espejo, Cruz, Walter e Gassner (2009), Walter, Cruz, Espejo e Gassner (2009), Guimarães, Gomes, Odelius, Zancan e Corradi (2009) e Nascimento, Santos, Rengel e Beuren (2009). Dos estudos internacionais destacam-se os de Larivière, Gingras e Archambault (2005), Acedo, Barroso, Casanueva e Galán (2006), Olmeda-Gómez, Perianes-Rodriguez, Ovalle-Perandones, Guerrero-Bote e Anegón (2009). Esta pesquisa diferencia-se das demais ao proporcionar, por meio de um estudo bibliométrico e sociométrico, auxiliado pela análise de redes de sociais (ARS), uma visão panorâmica acerca da produção científica publicada em periódicos do Qualis CAPES e da interação dos programas de pós-graduação em ciências contábeis no Brasil que veiculam sua produção científica intelectual nestes periódicos.

Walter et al. (2009, p. 2) destacam que as pesquisas desta natureza demonstram sua relevância em "servir de instrumento de diagnóstico para a investigação do fortalecimento de programas de pósgraduação em ciências contábeis, especialmente as que possuem linha de pesquisa na área de ensino e pesquisa". Os autores ressaltam ainda que estes estudos podem contribuir para ampliar o efeito multiplicador destes programas, além de auxiliá-los no cumprimento das propostas pedagógicas e científicas. Silva et al. (2006) asseveram que, por meio da análise de redes sociais formadas pelos pesquisadores, é possível detectar a estrutura e a evolução científica de um campo de conhecimento, impulsionado pelos aspectos interdisciplinares. 
O estudo está estruturado em seis seções, iniciando com esta de caráter introdutório. A segunda seção demonstra a importância das redes sociais na produção científica. A terceira seção apresenta estudos anteriores realizados sobre esta temática em âmbito nacional e internacional. A quarta seção aborda a metodologia da pesquisa adotada na investigação. A quinta seção apresenta a análise dos dados coletados. Por fim, a sexta seção expõe as conclusões do estudo e recomendações para pesquisas futuras.

\section{Redes Sociais na Produção Científica}

A Análise de Redes Sociais (ARS) é proveniente da expressão inglesa Social Network Analysis (SNA) (Silva et al., 2006). Burt (1992), Miles e Snow (1992), Nohria (1992), Nooteboom, Hans e Niels (1997) e Uzzi (1997) conceituam redes como um padrão de cooperação e/ou troca especial de alianças interfirmas e/ou intrafirmas. Wasserman e Faust (1994) entendem por redes sociais o conjunto finito de atores e as relações que ocorrem entre eles. Fonseca e Machado-da-Silva (2002) destacam que, por meio das redes de relacionamento, se pode observar os valores/crenças e regras, que transmitem conceitos sobre modos apropriados de fazer e agir de um determinado grupo.

Silva et al. (2006, p. 77) explicam que as redes "são sistemas compostos por 'nós' e conexões entre eles, que, nas ciências sociais, são representados por sujeitos sociais (indivíduos, grupos, organizações etc.) conectados por algum tipo de relação". Martins (2009, p. 42) as conceitua como o "conjunto de contatos que ligam vários atores, nos quais tais contatos podem ser de diferentes tipos, por apresentarem conteúdos diferentes e apresentarem diferentes propriedades estruturais". Portanto, redes sociais são as ligações oriundas da rede de relacionamento estabelecidas pelos indivíduos e/ou organizações, dentro e fora de determinado ambiente analisado.

De acordo com Silva et al. (2006), a utilização das redes sociais na análise da produção científica permite a observação de aspectos interdisciplinares decorrentes da colaboração dos pesquisadores, além de proporcionar a análise e estruturação de um dado campo do conhecimento. Burt (1992) destaca que as redes sociais possibilitam as trocas de informações entre os atores que as compõem e o ambiente onde eles estão insertos. Sobre a importância em se entender os relacionamentos interorganizacionais, assim como as ligações provenientes, tanto de dependência como de interdependência dos pesquisadores de redes, tem prevalecido o interesse pelas trocas de informações na configuração das redes sociais (Maciel, 2007).

A formação das redes sociais necessita dos seguintes elementos, de acordo com Wasserman e Faust (1994): ator, nós, laço relacional (ligações fortes ou fracas), díade, tríade, grupo e centralidade. Além desses elementos acrescentam-se ainda as lacunas estruturais que permeiam as redes de colaboração. Wasserman e Faust (1994) definem os atores como entidades sociais que possuem ligações na rede. Estes atores também representam os nós contemplados na rede de colaboração, em que cada ator colabora em pelo menos um dos itens de uma rede (Hanneman \& Riddle, 2005; Wasserman \& Fast, 1994).

Os laços relacionais representam a coleção de laços de um tipo específico entre os membros de um grupo, que está sendo representado pelas ligações entre os atores (Wasserman \& Fast, 1994). Estes laços relacionais ou ligações que ocorrem entre os atores de uma rede social podem caracterizar-se por meio de laços fortes ou fracos. Os laços fortes correspondem a uma rede social compreendida de um mesmo indivíduo e os demais atores que formam uma densa malha de relacionamentos, em que muitos dos possíveis laços relacionais estão presentes. Os laços fracos, conforme Granovetter (1983), são os menos suscetíveis de serem socialmente envolvidos numa rede social de baixa densidade, ou seja, uma rede em que muitas das possíveis linhas relacionais estão ausentes. Espejo et al. (2009, p. 12) explicam que "os laços fracos representam laços indiretos, operacionalizados por meio da interação de um autor que publica com outros pesquisadores". 
Relativamente à quantidade de atores que se relacionam há ligações díades e tríades. As díades ocorrem quando há ligações entre apenas dois atores numa unidade de análise e as tríades estão presentes nas ligações entre três ou mais atores (Wasserman \& Fast, 1994). Os grupos têm sua origem nas relações que possuem laços mensuráveis, caracterizando-se por um conjunto finito de atores definidos por critérios conceituais, teóricos ou empíricos (Wasserman \& Fast, 1994). Compreendem ligações estabelecidas por vários atores simultaneamente e correspondem ao conjunto estudado. A centralidade consiste em identificar os atores mais importantes em uma rede social. Quanto mais centrais são estes atores na rede social, mais evidenciam sua importância (Wasserman \& Fast, 1994). As lacunas estruturais promovem uma vantagem competitiva para os atores que realizam conexões com diversos atores simultaneamente, uma vez que os indivíduos não conectados não possuem acesso às informações partilhadas por estes atores e acabam por permanecer à margem desta rede de relacionamento (Burt, 1992).

Pesquisadores utilizam as redes sociais, pois entendem que elas evidenciam os relacionamentos interorganizacionais (Maciel, 2007). Silva et al. (2006) mencionam que nas redes sociais formadas por pesquisadores sobressaem as redes de coautoria. Nestas redes os atores são os docentes e/ou pesquisadores; as conexões entre eles ocorrem sempre que partilham a autoria de um artigo científico. "A visualização da rede, na forma de gráficos é considerada, pelos autores da área, mais intuitiva do que a visualização na forma de matrizes" (Silva et al. 2006, p. 78).

Guimarães et al. (2009, p. 1) destacam que uma rede entre os programas de pós-graduação "pode constituir-se condição ideal para aumentar o volume e a qualidade da produção científica brasileira". As redes sociais podem ser estabelecidas em todos os ambientes, até mesmo no acadêmico, por meio da cooperação entre os pesquisadores com intuito de disseminar o conhecimento científico.

\section{Pesquisas Anteriores com Redes Sociais de Produção Científica}

Nos últimos anos, pesquisadores de vários campos do conhecimento têm seu interesse revitalizado nos estudos das redes sociais, na tentativa de compreender o seu impacto sobre a vida social, dando origem a inúmeras metodologias de análise que têm por base as relações sociais entre os indivíduos, em forma de redes (Silva et al., 2006). Assim, algumas pesquisas têm sido realizadas sobre as redes sociais no âmbito da produção científica. Dentre os estudos nacionais podem-se mencionar os realizados por Maia e Caregnato (2008), Espejo et al. (2009), Walter et al. (2009), Guimarães et al. (2009) e Nascimento et al. (2009).

Maia e Caregnato (2008) analisaram as redes de colaboração científica entre os docentes do programa de pós-graduação em epidemiologia da Universidade Federal de Pelotas. Destaca-se que as características pertinentes à colaboração científica foram estudadas por meio das coautorias dos artigos publicados em periódicos no período de 1991 a 2002. A partir dos achados da pesquisa observaram que os docentes analisados publicaram mais artigos em autoria compartilhada do que individual. Não foi detectada relação entre o aumento de produtividade e o número de colaboradores. Constataram ainda que a configuração das redes sociais concentra-se em torno dos docentes mais produtivos.

Espejo et al. (2009) identificaram os autores e as instituições de destaque envolvidos no campo de pesquisa em contabilidade no período entre 2004 e 2008, na perspectiva da teoria institucional. Analisaram 825 artigos científicos dos seguintes periódicos: Revista de Contabilidade \& Finanças e Revista BASE, além dos artigos provenientes dos anais do EnANPAD e do Congresso USP de Controladoria e Contabilidade. Os resultados revelaram que a rede de cooperação, quanto ao ensino e pesquisa se apresenta com ligações mais dispersas. Entretanto, as redes de contabilidade gerencial e usuários externos demonstraram um número maior de ligações, mas com laços fracos. Constataram ainda a existência de redes de cooperação com número elevado de ligações entre autores e instituições nacionais, todavia isto não foi observado com instituições internacionais. 
Walter et al. (2009) identificaram os atores mais relevantes na evolução do campo da produção científica em ensino e pesquisa contábil no contexto brasileiro. Analisaram 139 artigos científicos publicados de 2004 a 2008 em quatro fontes de dados: Revista de Contabilidade \& Finanças; Revista BASE, Encontro da Associação Nacional de Pós-Graduação e Pesquisa em Administração (EnANPAD) e Congresso USP de Controladoria e Contabilidade. Os resultados demonstraram uma relativa evolução da pesquisa contábil quanto às instituições e autores investigados, no que tange ao número de artigos publicados e à densidade das redes de cooperação. Porém, os autores destacaram que as redes de cooperação com instituições internacionais podem ser aperfeiçoadas.

Nascimento et al. (2009) analisaram as redes de pesquisa formadas entre os egressos do curso de doutorado em ciências contábeis da FEA/USP. Os resultados demonstraram que a Universidade de São Paulo possui nas redes o maior número de egressos, sendo na maioria docentes. Observaram ainda que a maior parte da produção científica destes egressos classifica-se como produção científica provisória, por destinar-se às publicações em eventos científicos. Constataram também que a rede de cooperação entre esses egressos se apresenta com ligações fracas em livros, capítulos de livros e textos de revistas/jornais; e relações de cooperação forte na publicação de artigos em periódicos.

Embora realizada na área da administração, destaca-se a pesquisa de Guimarães et al. (2009) pelo fato de ter investigado a formação de redes sociais entre pesquisadores de programas de pósgraduação. $\mathrm{O}$ estudo investigou a influência de relações acadêmicas e de atributos de programas de pós-graduação em administração na estrutura da rede desses programas, apoiada na abordagem de redes sociais. Os achados da pesquisa mostraram que a rede pesquisada é pouco densa, com relações esparsas e, na maioria das vezes, fracas entre programas. Constataram que o programa da UFRGS é o mais central da rede e os programas da FGV/SP, USP/SP, UFRGS e FGV/RJ foram os mais prestigiados.

Em âmbito internacional pesquisas também têm sido realizadas sobre redes sociais na produção científica de diferentes áreas. Para ilustrar pesquisas relativamente a redes de colaboração, citam-se os estudos realizados por Larivière et al. (2005), Acedo et al. (2006), Olmeda-Gómez et al. (2009).

Larivière et al. (2005) preocuparam-se com a dicotomia básica existente entre as práticas de publicações nas ciências naturais e engenharia e as ciências sociais e humanas para identificar os padrões de colaboração entre estas áreas do conhecimento. Pesquisaram as bases de dados do Science Citation Index, Social Sciences Citatition Index e Art \& Humanities Citation Index, referentes ao período de 1980 a 2002. Os resultados revelaram que as relações de colaboração dos pesquisadores canadenses estão crescendo nas ciências naturais e engenharia, bem como nas ciências sociais e humanas. Verificaram também uma tendência ascendente em colaboração internacional. Ainda, que a expressão mais visível da colaboração científica é a coautoria, pois quase todos os artigos das ciências naturais e engenharias são publicados em conjunto, em comparação com dois terços nas ciências sociais e cerca de $10 \%$ na área de humanas.

Acedo et al. (2006) realizaram análise exploratória de coautoria no domínio da gestão de duas abordagens voltadas à colaboração do conhecimento científico, sendo a primeira voltada para analisar as razões pelas quais os autores colaboram e as consequências dessa decisão e a segunda tem como base a ideia que a coautoria cria uma rede social dos pesquisadores. A pesquisa foi realizada no banco de dados da Social Sciences Citation Index (SSCI) na sua versão eletrônica Web of Science, sendo analisados dez periódicos americanos e as principais revistas europeias que versam sobre estudos organizacionais durante o período de 1980 a 2002, compreendendo um total de 14.597 documentos analisados (artigos, notas de pesquisa, editorias, entre outras). Os achados da pesquisa demonstram uma tendência crescente na coautoria dos trabalhos como em outras áreas do conhecimento. Observaram ainda que a análise de redes permite a exploração das particularidades da gestão em relação aos outros campos de conhecimento, bem como as ligações existentes entre os autores centrais que ocupam posição de destaque dentro dessa disciplina.

Olmeda-Gómez et al. (2009) analisaram as relações entre as universidades espanholas e as redes de colaboração internacional geradas por estas instituições com base na análise da coautoria de artigos 
científicos. Investigaram a produção científica do período de 2000 a 2004 a partir da coautoria dos artigos científicos indexados na base de dados da Web of Science com auxílio das redes sociais. Os resultados da pesquisa mostraram que os padrões de colaboração entre as universidades espanholas são influenciados pela proximidade geográfica e a afiliação político administrativa. Nas relações interregionais de coautoria verificaram a formação de sub-redes regionais aproximadas por divisões geopolíticas. Nas relações internacionais constataram a colaboração com a União Europeia, América do Norte e alguns pesquisadores latinos. Maior visibilidade da produção científica espanhola foi vislumbrada pelas coautorias internacionais do que com qualquer outro tipo de colaboração analisada. O impacto de coautoria foi mensurado a partir de periódicos científicos, ao invés de cada pesquisador individualmente.

\section{Metodologia da Pesquisa}

Estudo descritivo foi realizado para identificar a formação das redes sociais na produção científica definitiva do triênio 2007-2009 dos programas de pós-graduação de ciências contábeis do Brasil. Cervo e Bervian (1996) explicam que as pesquisas dessa natureza são responsáveis por observar, registrar, analisar e correlacionar os fatos ou fenômenos sem manipulá-los.

Pesquisa documental foi utilizada no estudo bibliométrico e sociométrico. Martins e Theóphilo (2007) destacam que a pesquisa documental realiza levantamento de material editado, como livros e periódicos, entre outros. Por sua vez, as pesquisas bibliométricas, conforme Macia-Chapula (1998, p. 134), compreendem "o estudo dos aspectos quantitativos da produção, disseminação e uso da informação registrada". No que concerne às pesquisas sociométricas, elas se voltam à exploração da matriz de relacionamentos oriundas dos atores sociais (Galaskiewcz \& Wasserman, 1994).

A população da pesquisa compreendeu os 24 cursos de mestrado e doutorado em ciências contábeis recomendados pela CAPES (2010). Para fins da pesquisa, foi excluído o doutorado em ciências contábeis e administração da FUCAPE, por ter sido aprovado no segundo semestre de 2009. Pelo mesmo motivo foi excluído da pesquisa o mestrado em ciências contábeis da Universidade Federal do Espírito Santo (UFES). O mestrado da Universidade Federal do Ceará foi excluído da pesquisa por ter assumido nova configuração em 2008 e estar sem o histórico de dados necessário para esta pesquisa.

A Tabela 1 apresenta os 17 programas de pós-graduação em ciências contábeis que compreendem a amostra deste estudo, de acordo com a listagem disponibilizada em 8 de agosto de 2009 pela Coordenação de Aperfeiçoamento de Pessoal de Nível Superior (CAPES), órgão que reconhece, coordena e monitora o desempenho dos programas de pós-graduação em âmbito nacional.

Tabela 1

Programas de Pós-Graduação em Ciências Contábeis que Compõem a Amostra da Pesquisa

\begin{tabular}{ccclc}
\hline Qtde. & $\begin{array}{c}\text { Programa de pós- } \\
\text { graduação }\end{array}$ & Curso & \multicolumn{1}{c}{ Universidade } & Estado \\
\hline & Ciências Contábeis & Mestrado & $\begin{array}{l}\text { Fundação Instituto Capixaba de Pesquisa em } \\
\text { Contabilidade, Economia e Finanças (FUCAPE) }\end{array}$ & ES \\
& & Mestrado & Fundação Instituto Capixaba de Pesquisa em & \\
1 & Ciências Contábeis & Profissional & Contabilidade, Economia e Finanças (FUCAPE) & ES \\
2 & Ciências Contábeis & Mestrado & Universidade Federal de Minas Gerais (UFMG) & MG \\
3 & Ciências Contábeis & Mestrado & Universidade Federal de Pernambuco (UFPE) & PE \\
\hline
\end{tabular}


Tabela 1 (continuação)

\begin{tabular}{|c|c|c|c|c|}
\hline Qtde. & $\begin{array}{l}\text { Programa de pós- } \\
\text { graduação }\end{array}$ & Curso & Universidade & Estado \\
\hline 4 & Ciências Contábeis & Mestrado & Universidade Federal do Rio de Janeiro (UFRJ) & RJ \\
\hline 5 & Ciências Contábeis & Mestrado & Universidade Estadual do Rio de Janeiro (UERJ) & $\mathrm{RJ}$ \\
\hline \multirow[t]{2}{*}{6} & Ciências Contábeis & Mestrado & $\begin{array}{l}\text { Universidade do Vale do Rio dos Sinos } \\
\text { (UNISINOS) }\end{array}$ & $\mathrm{RS}$ \\
\hline & Ciências Contábeis & Mestrado & Universidade Regional de Blumenau (FURB) & $\mathrm{SC}$ \\
\hline 7 & Ciências Contábeis & Doutorado & Universidade Regional de Blumenau (FURB) & $\mathrm{SC}$ \\
\hline 8 & Ciências Contábeis & Mestrado & Universidade Presbiteriana Mackenzie (UPM) & SP \\
\hline 9 & Ciências Contábeis & Mestrado & $\begin{array}{l}\text { Centro Universitário Álvares Penteado } \\
\text { (UNIFECAP) }\end{array}$ & SP \\
\hline 10 & $\begin{array}{l}\text { Ciências Contábeis e } \\
\text { Atuarias }\end{array}$ & Mestrado & $\begin{array}{l}\text { Pontifícia Universidade Católica de São Paulo } \\
\text { (PUC-SP) }\end{array}$ & SP \\
\hline 11 & Contabilidade & Mestrado & Universidade Federal da Bahia (UFBA) & BA \\
\hline 12 & Contabilidade & Mestrado & Universidade Federal do Paraná (UFPR) & PR \\
\hline \multirow[t]{2}{*}{13} & Contabilidade & Mestrado & Universidade Federal de Santa Catarina (UFSC) & SC \\
\hline & Contabilidade & Mestrado & Universidade de Brasília (UNB) & $\mathrm{DF}$ \\
\hline 14 & Contabilidade & Doutorado & Universidade de Brasília (UNB) & DF \\
\hline \multirow[t]{2}{*}{15} & $\begin{array}{l}\text { Contabilidade e } \\
\text { Controladoria }\end{array}$ & $\begin{array}{l}\text { Mestrado } \\
\text { Profissional }\end{array}$ & Universidade Federal da Amazônia (UFAM) & $\mathrm{AM}$ \\
\hline & $\begin{array}{l}\text { Controladoria e } \\
\text { Contabilidade }\end{array}$ & Mestrado & Universidade de São Paulo (USP) & SP \\
\hline 16 & $\begin{array}{l}\text { Controladoria e } \\
\text { Contabilidade }\end{array}$ & Doutorado & Universidade de São Paulo (USP) & SP \\
\hline 17 & $\begin{array}{l}\text { Controladoria e } \\
\text { Contabilidade }\end{array}$ & Mestrado & $\begin{array}{l}\text { Universidade de São Paulo - Campus Ribeirão } \\
\text { Preto (USP/RP) }\end{array}$ & SP \\
\hline
\end{tabular}

Nota. Fonte: Coordenação de Aperfeiçoamento de Pessoal de Nível Superior. (2009). Relação de cursos recomendados e reconhecidos. $\quad$ Recuperado $\quad 8$ em $\quad 8$ agosto, $\quad 2009, \quad$ de http://conteudoweb.capes.gov.br/conteudoweb/ProjetoRelacaoCursosServlet?acao=pesquisarIes\&codigoArea=60200006\&de scricaoArea=CI\%CANCIAS+SOCIAIS+APLICADAS+\&descricaoAreaConhecimento=ADMINISTRA\%C7\%C3O\&descric aoAreaAvaliacao $=\mathrm{ADMINISTRA} \% \mathrm{C} 7 \% \mathrm{C} 3 \mathrm{O} \% 2 \mathrm{C}+\mathrm{CI} \% \mathrm{CANCIAS}+\mathrm{CONT} \% \mathrm{C} 1 \mathrm{BEIS}+\mathrm{E}+\mathrm{TURISMO}$

Após a seleção dos programas de pós-graduação em ciências contábeis, buscou-se a relação dos professores permanentes que compõem o corpo docente destes programas. Conforme Portaria CAPES (n. 68/2004), enquadram-se na categoria de docentes permanentes, os professores que, além do vínculo empregatício (CLT ou servidor público), com regime mínimo de 40 horas semanais, com o programa que recebem bolsa de fixação de docentes ou sejam pesquisadores de agências federais ou estaduais de fomento, e quando na qualidade de professor ou pesquisador aposentado, tenham firmado com a instituição termo de compromisso de participação como docente do programa ou tenham sido cedidos, por convênio formal, para atuar como docente do programa.

Nos sites dos programas identificaram-se os docentes que se enquadravam nesta categoria. Para os programas que não apresentaram esta informação de forma explícita na sua home page, a informação foi solicitada para as secretarias dos respectivos cursos via correio eletrônico no mês de agosto de 2009. Assim, chegou-se a 199 docentes permanentes distribuídos nos 21 cursos dos 17 programas investigados. 
A coleta dos dados referente à produção científica definitiva do triênio 2007-2009 dos docentes permanentes foi realizada na Plataforma Lattes (http://lattes.cnpq.br/), no período de 10 a 13 de agosto de 2009 e complementada no período de 02 a 04 de fevereiro de 2010. De acordo com a CAPES (2010), a produção científica qualificada como definitiva compreende os artigos publicados em periódicos, artigos aceitos para publicação em periódicos, livros e capítulos de livros. Optou-se por pesquisar a produção científica definitiva dos artigos publicados e aceitos para publicação em periódicos, uma vez que a CAPES ainda não havia divulgado na data da pesquisa a tabela de pontuação para as produções científicas relativas a livros e capítulos de livros, que também se configuram como definitivas.

Quanto aos procedimentos adotados na análise quantitativa dos dados, utilizou-se da estatística descritiva para quantificação da produção científica permanente, disponível nos currículos destes docentes. E na análise das redes sociais estabelecidas entre os docentes e seus respectivos programas recorreu-se ao software UNICET®.

\section{Análise dos Dados}

Na descrição e análise dos dados coletados evidencia-se a evolução da produção científica definitiva dos programas de pós-graduação investigados; a veiculação da produção científica dos programas nos periódicos classificados pelo Qualis/CAPES; por fim, a rede de pesquisa formada pelos programas de pós-graduação no triênio 2007-2009.

\section{Evolução da produção científica definitiva dos programas de pós-graduação em ciências contábeis no triênio 2007-2009}

Na Tabela 2 apresenta-se a evolução da produção científica definitiva dos programas de pósgraduação em ciências contábeis, compreendendo os artigos científicos publicados e os aceitos para publicação em periódicos no triênio 2007-2009.

Tabela 2

Evolução da Produção Científica Definitiva dos Programas de Pós-Graduação em Ciências Contábeis no Triênio 2007-2009

\begin{tabular}{|c|c|c|c|c|c|c|c|c|}
\hline Programas & $\begin{array}{c}\mathbf{N}^{\circ} \text {. } \\
\text { Docentes }\end{array}$ & Conceitos & $\begin{array}{l}\text { Pont. } \\
\text { Total } \\
2007\end{array}$ & $\begin{array}{l}\text { Pont. } \\
\text { Total } \\
2008\end{array}$ & $\begin{array}{l}\text { Pont. } \\
\text { Total } \\
2009\end{array}$ & $\begin{array}{l}\Delta(\%) \\
2007- \\
2008\end{array}$ & $\begin{array}{c}\Delta(\%) \\
2008- \\
2009\end{array}$ & $\begin{array}{l}\Delta(\%) \\
2007- \\
2009\end{array}$ \\
\hline FUCAPE & 13 & 4 & 800 & 1030 & 420 & $28,75 \%$ & $-59,22 \%$ & $-47,50 \%$ \\
\hline FURB & 12 & $3 / 4$ & 1180 & 1070 & 1350 & $-9,32 \%$ & $26,17 \%$ & $14,41 \%$ \\
\hline PUC-SP & 10 & 3 & 490 & 400 & 260 & $-18,37 \%$ & $-35,00 \%$ & $-46,94 \%$ \\
\hline UERJ & 12 & 3 & 90 & 270 & 180 & $200,00 \%$ & $-33,33 \%$ & $100,00 \%$ \\
\hline UFAM & 12 & 3 & 30 & - & 30 & $-100,00 \%$ & - & $0,00 \%$ \\
\hline UFBA & 11 & 3 & 390 & 150 & 610 & $-61,54 \%$ & $306,67 \%$ & $56,41 \%$ \\
\hline UFMG & 13 & 3 & 700 & 1010 & 790 & $44,29 \%$ & $-21,78 \%$ & $12,86 \%$ \\
\hline UFPE & 13 & 3 & 540 & 810 & 430 & $50,00 \%$ & $-46,91 \%$ & $-20,37 \%$ \\
\hline UFPR & 11 & 3 & 90 & 120 & 180 & $33,33 \%$ & $50,00 \%$ & $100,00 \%$ \\
\hline
\end{tabular}


Tabela 2 (continuação)

\begin{tabular}{|c|c|c|c|c|c|c|c|c|}
\hline Programas & $\begin{array}{c}\mathrm{N}^{\mathbf{}} \text {. } \\
\text { Docentes }\end{array}$ & Conceitos & $\begin{array}{l}\text { Pont. } \\
\text { Total } \\
2007\end{array}$ & $\begin{array}{l}\text { Pont. } \\
\text { Total } \\
2008\end{array}$ & $\begin{array}{l}\text { Pont. } \\
\text { Total } \\
2009\end{array}$ & $\begin{array}{c}\Delta(\%) \\
2007- \\
2008\end{array}$ & $\begin{array}{c}\Delta(\%) \\
2008- \\
2009\end{array}$ & $\begin{array}{c}\Delta(\%) \\
2007- \\
2009\end{array}$ \\
\hline UFRJ & 10 & 4 & 580 & 470 & 760 & $-18,97 \%$ & $61,70 \%$ & $31,03 \%$ \\
\hline UFSC & 10 & 3 & 880 & 730 & 520 & $-17,05 \%$ & $-28,77 \%$ & $-40,91 \%$ \\
\hline UNB & 16 & 4 & 560 & 650 & 530 & $16,07 \%$ & $-18,46 \%$ & $-5,36 \%$ \\
\hline UNIFECAP & 10 & 3 & 380 & 230 & 410 & $-39,47 \%$ & $78,26 \%$ & $7,89 \%$ \\
\hline UNISINOS & 9 & 4 & 370 & 460 & 690 & $24,32 \%$ & $50,00 \%$ & $86,49 \%$ \\
\hline UPM & 10 & 4 & 950 & 550 & 620 & $-42,11 \%$ & $12,73 \%$ & $-34,74 \%$ \\
\hline USP & 19 & 5 & 2250 & 1850 & 1100 & $-17,78 \%$ & $-40,54 \%$ & $-51,11 \%$ \\
\hline USP-RP & 8 & 3 & 210 & 910 & 930 & $333,33 \%$ & $2,20 \%$ & $342,86 \%$ \\
\hline
\end{tabular}

Nota. Fonte: Coordenação de Aperfeiçoamento de Pessoal de Nível Superior. (2009). Relação de cursos recomendados e $\begin{array}{llllll}\text { reconhecidos. } & \text { Recuperado } & \text { em } & 8 & \text { agosto, } & \text { 2009, }\end{array}$ http://conteudoweb.capes.gov.br/conteudoweb/ProjetoRelacoaCursosServlet?Ação-persiarles\&codigoArea60200006\&descricaoArea-CI\%CANCIAS+SOCIAIS+APLICADAS+CONT\%CIBEIS+E+TURISMO

Com base nas publicações relatadas pelos docentes permanentes dos programas em seu $C V$ Lattes, as pontuações dispostas na Tabela 2 foram calculadas tendo como referência a tabela de pontuação de periódicos veiculada pela CAPES no WebQualis (http://qualis.capes.gov.br/webqualis) do triênio 2007-2009.

O programa da Universidade de São Paulo de Ribeirão Preto (USP-RP) apresentou a maior variação percentual com valores positivos, demonstrando expressivo crescimento em termos percentuais de 2007-2008 (333,33\%) e 2008-2009 (2,20\%), totalizando 342,86\% no triênio. Na sequência está o programa da Universidade do Estado do Rio de Janeiro (UERJ), que apresentou uma variação percentual de $100 \%$ no triênio; no ano de 2009 apresentou um declínio em termos percentuais de $-33,33 \%$. Em seguida aparecem os programas das Universidades do Vale do Rio dos Sinos (UNISINOS) e a Universidade Federal da Bahia (UFBA), com variação no triênio de 86,49\% e $56,41 \%$ respectivamente.

Infere-se que, de modo geral, os programas com conceito 3 na CAPES apresentaram maior crescimento em termos percentuais que os programas de conceito mais elevado, tais como USP, FUCAPE, UPM e UNB, que demonstraram variação negativa no triênio; a FURB e a UFRJ mantiveram-se em patamares positivos.

\section{Veiculação da produção científica definitiva dos programas nos periódicos classificados pelo Qualis CAPES}

A Coordenação de Aperfeiçoamento de Pessoal de Nível Superior desenvolveu um conjunto de procedimentos a serem seguidos pelos programas de pós-graduação, entre eles gerou o Qualis para segmentar a qualidade da produção intelectual por meio dos estratos indicativos da qualidade. Para auferir a qualidade da produção científica, veiculada nos periódicos, considera-se como estágio mais elevado A1 com 100 pontos, seguido pelo A2 (80 pontos), B1 (60 pontos), B2 (50 pontos), B3 (30 pontos), B4 (20 pontos), B5 (10 pontos) e C com pontuação igual a zero (CAPES, 2010).

Para melhor entendimento acerca da veiculação da produção científica definitiva dos programas de pós-graduação em ciências contábeis procurou-se dividir esta seção em subitens de acordo com o Qualis CAPES. 


\section{Periódicos classificados como A1 e A2}

A Figura 1 demonstra as redes sociais formadas a partir dos artigos publicados nos periódicos classificados pelo Qualis CAPES como A1 e A2. Para a construção das redes sociais consideraram-se somente os docentes dos programas analisados, sendo excluídos os alunos, professores e pesquisadores de outras instituições que não pertencem a algum dos cursos de mestrado e doutorado em ciências contábeis pesquisados.

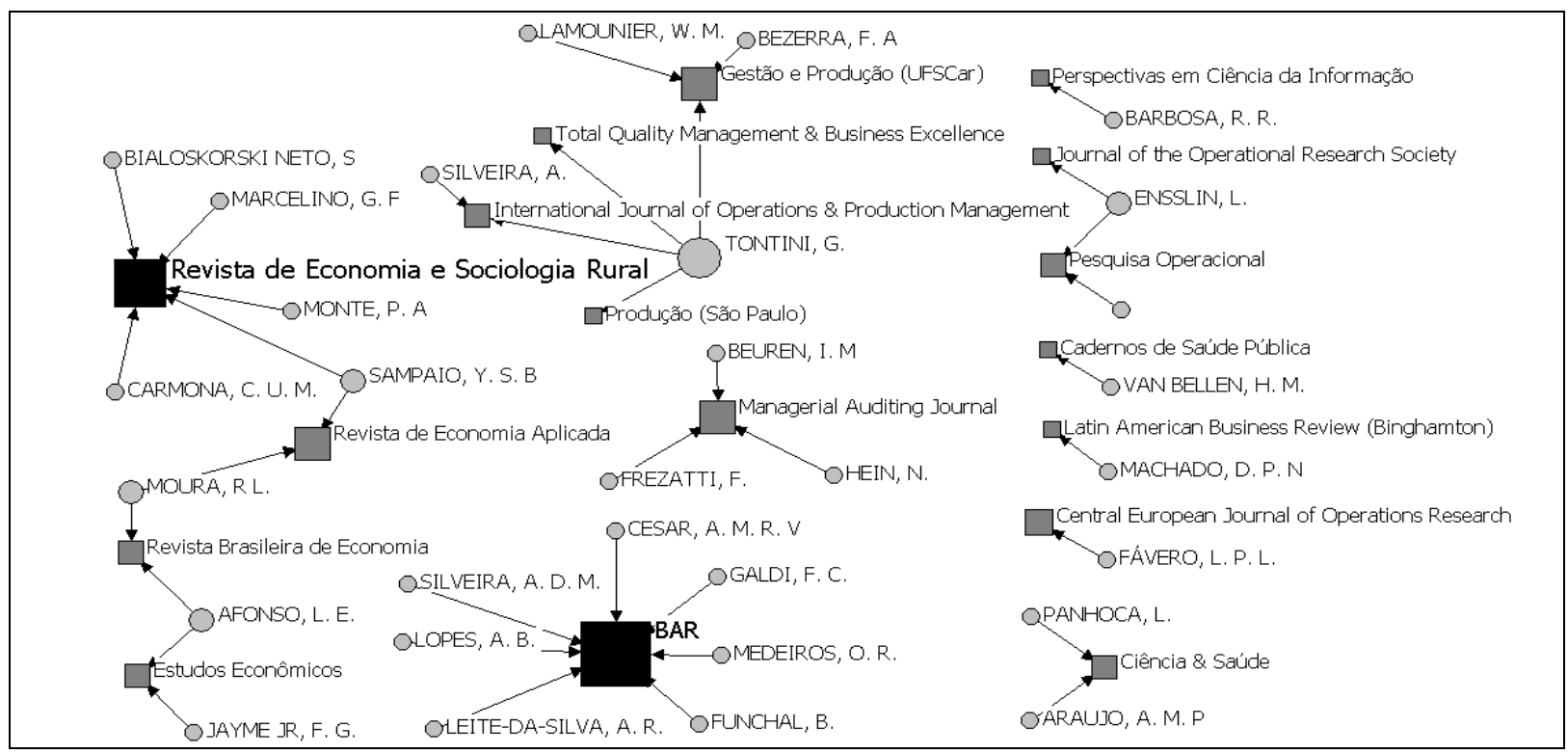

Figura 1. Redes sociais das publicações nos periódicos classificados como A1 e A2.

Nota. Fonte: dados da pesquisa.

Para fins de análise da formação de redes, a posição central de uma rede social é medida pelo número de laços que um ator possui com outros atores (participantes) de uma rede social (Wasserman \& Fast, 1994). Neste sentido, infere-se que os atores que ocupam a posição central por apresentarem o maior número de ligações com os outros atores, ou seja, conseguem difundir melhor suas ideias principalmente na sua comunidade científica. Nesta etapa do estudo focaliza-se a análise por periódico das publicações dos atores pesquisados, a fim de verificar as redes sociais formadas nesses meios de divulgação.

A ideia de focalizar os periódicos (meio de divulgação) na análise da coautoria de artigos científicos surgiu a partir da leitura da pesquisa de Olmeda-Gómez et al. (2009), que nas relações inter-regionais de coautoria verificaram a formação de sub-redes regionais aproximadas por divisões geopolíticas. Processo semelhante de formação de redes e sub-redes pode ocorrer com as publicações em um mesmo periódico.

Na Figura 1 observa-se que a centralidade da rede é ocupada pelo periódico Brazilian Administration Review (BAR), com publicações trimestrais; cada edição contempla em média cinco artigos. Após consta a Revista de Economia e Sociedade Rural, classificada como A2, que possui publicações trimestrais com uma média de 10 artigos por edição. Alguns docentes também realizaram publicações em periódicos internacionais, tais como: Managerial Auditing Journal, International Journal of Operations \& Production Management, Latin American Business Review, Total Quality Management \& Business, Central European Journal of Operations Research, Journal of the Operational Research Society.

A Tabela 3 apresenta os docentes que publicaram artigos nos periódicos que ocuparam a posição central da rede social. 
Tabela 3

Docentes que Publicaram nos Periódicos A1 e A2 que Ocuparam a Centralidade da Rede Social

\begin{tabular}{clll}
\hline Periódico & & Docentes & Instituição \\
\hline \multirow{2}{*}{ BAR } & LEITE-DA-SILVA, A. R. & Alfredo Rodrigues Leite da Silva & FUCAPE \\
& FUNCHAL, B. & Bruno Funchal & FUCAPE \\
& MEDEIROS, O. R. & Otávio Ribeiro de Medeiros & UNB \\
& CESAR, A. M. R. V. & Ana Maria R. V. Coelho César & UPM \\
& LOPES, A. B. & Alexsandro Broedel Lopes & USP \\
& SILVEIRA, A. D. M. & Alexandre Di Miceli da Silveira & USP \\
\hline $\begin{array}{c}\text { Revista de } \\
\text { Eoconomia e }\end{array}$ & CARMONA, C. U. M. & Charles Ulises M. Carmona & UFPE \\
& SAMPAIO, Y. S. B. & Yony de Sá Barreto Sampaio & UFPE \\
& MARCELINO, A. F. & Paulo Aguiar do Monte & UNB \\
& BIALOSKORSKI NETO, S. & Sigismundo Bialoskorski Neto & USP-RP \\
\hline
\end{tabular}

Nota. Fonte: dados da pesquisa.

A Tabela 3 demonstra os periódicos que ocupam a centralidade da rede e os docentes que publicaram artigos nestes periódicos. Embora se tenha identificado a centralidade de redes ocupadas por determinados periódicos, os autores que neles publicam não se repetem, ao contrário das instituições, que aparecem mais de uma vez, devido a redes sociais entre os autores de uma mesma instituição.

\section{Periódicos classificados como B1}

A Figura 2 apresenta as redes sociais formadas a partir da produção científica definitiva dos programas de pós-graduação nos periódicos classificados como B1 conforme Qualis CAPES, cuja pontuação equivale a 60 pontos.

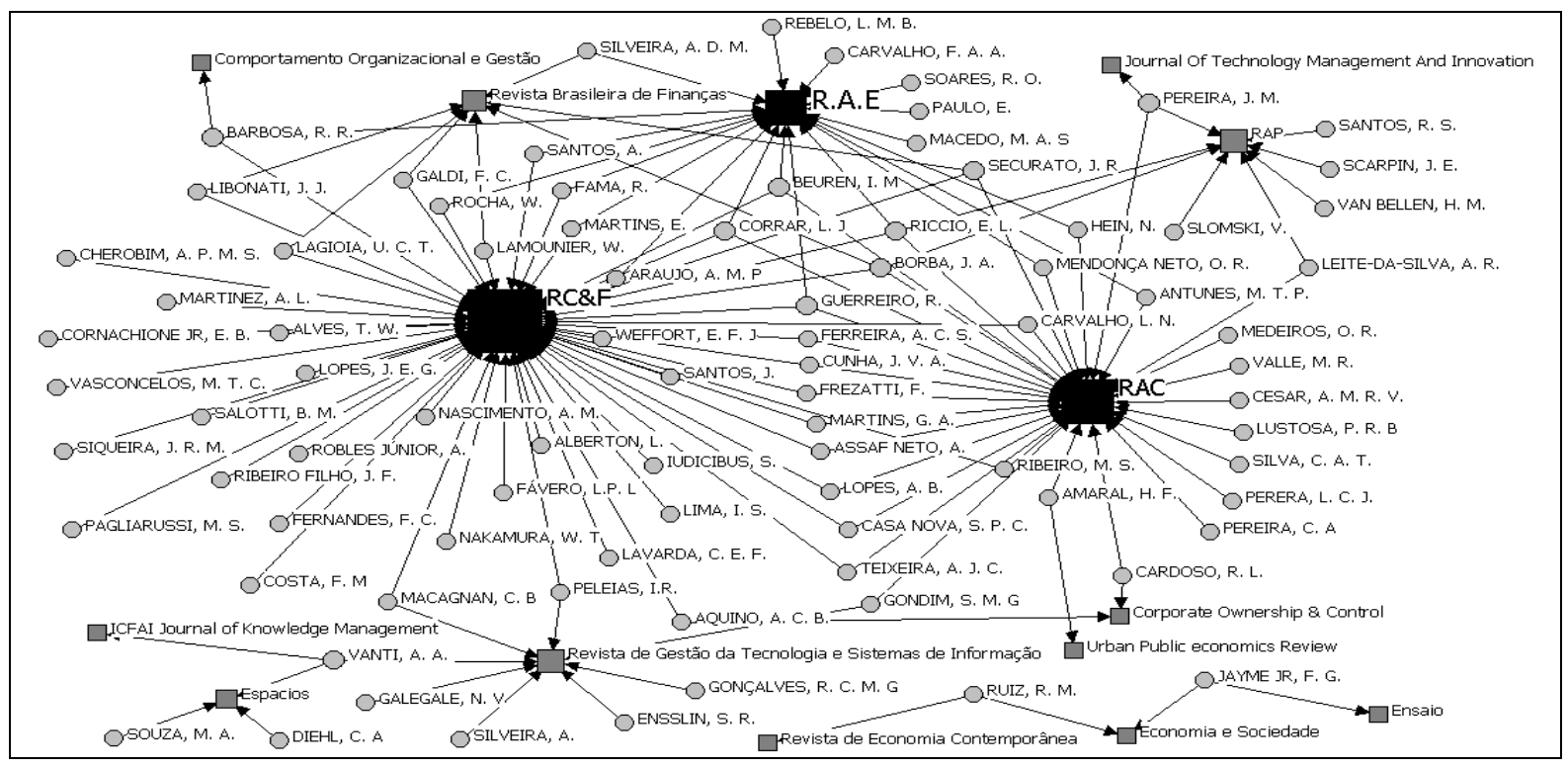

Figura 2. Redes sociais das publicações nos periódicos classificados como B1

Nota. Fonte: dados da pesquisa. 
Na Figura 2 nota-se que o periódico que ocupa a posição central da rede social é a Revista de Contabilidade \& Finanças (RC\&F), com publicações quadrimestrais e uma média de oito artigos por edição. Seguida, pela Revista de Administração Contemporânea (RAC) e Revista de Administração de Empresas (RAE). Dos 35 periódicos classificados como B1, a rede social é formada por 15 periódicos, sendo cinco destes internacionais (Comportamento Organizacional e Gestão - Portugal, Jornal of Technology Management and Innovation, Urban Public Economic Review, ICFAI Journal of Knowledge Management e Espacios).

Observa-se a criação de lacunas estruturais na rede social apresentada, uma vez que os atores (docentes) não realizam o compartilhamento de informações com o grupo, ou seja, deixam de publicar seus trabalhos científicos em outros periódicos deste estrato. Burt (1992) afirma que a existência de lacunas atua como uma vantagem competitiva para os atores que realizam a conexão entre as diferentes redes, haja vista que os indivíduos não conectados não realizam a troca de informações com os demais atores. Outro aspecto que se destaca é que a maioria dos periódicos da centralidade dessas redes, por exemplo, a Revista de Administração Contemporânea (RAC) e Revista de Administração de Empresas (RAE), não é específica de contabilidade, o que pode decorrer da pequena quantidade de periódicos de contabilidade classificada nesse estrato da CAPES.

\section{Periódicos classificados como B2}

A Figura 3 evidencia a rede social formada pela produção científica definitiva dos programas investigados tendo como referência os periódicos classificados no Qualis CAPES como B2, com pontuação correspondente a 50 pontos.

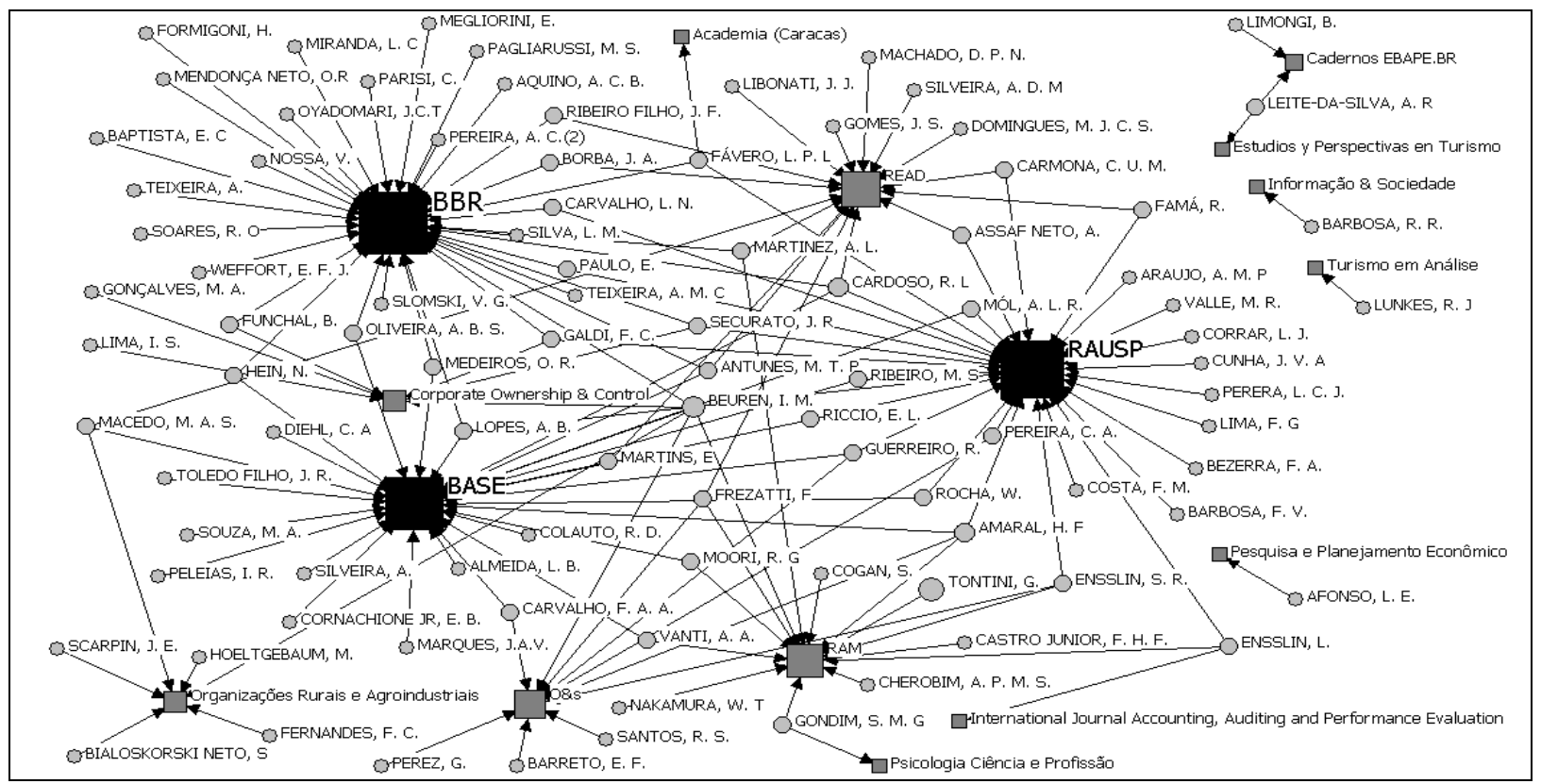

Figura 3. Redes sociais das publicações nos periódicos classificados como B2

Nota. Fonte: dados da pesquisa.

Nas redes sociais formadas a partir das publicações nos periódicos B2, a posição central é ocupada pela Brazilian Business Review (BBR), com publicações quadrimestrais e média de cinco artigos por edição. Na sequência, aparecem a Revista de Administração da USP (RAUSP) e a Revista Base da Unisinos (BASE). Os periódicos que sobressaíram são de áreas do conhecimento que tangenciam a contabilidade, por exemplo a Brazilian Business Review (BBR), que publica matérias de finanças e de contabilidade, e a Revista Base da Unisinos (BASE), que publica matérias de administração e de contabilidade. Isso sugere que os docentes dos Programas de Pós-Graduação em Ciências Contábeis também pesquisam em áreas multidisciplinares. 
Dos 44 periódicos que compõem este estrato do Qualis CAPES, a publicação científica definitiva dos programas de pós-graduação analisados concentra-se em 15 periódicos, sendo destes quatro internacionais (International Journal Accounting, Auditing and Performance Evaluation, Estúdios y Perspectivas en Turismo, Corporate Ownership \& Control), demonstrando a presença das lacunas estruturais nesta rede social. Neste caso não foram constatadas semelhanças com os achados da pesquisa de Larivière et al. (2005), que constataram na Espanha uma tendência ascendente de colaboração internacional na publicação científica.

\section{Periódicos classificados como B3}

A categoria B3, de acordo com a classificação do Qualis CAPES, compreende 38 periódicos científicos com pontuação equivalente a 30 pontos. A Figura 4 evidencia as redes sociais formadas pelos docentes dos programas de pós-graduação nestes periódicos.

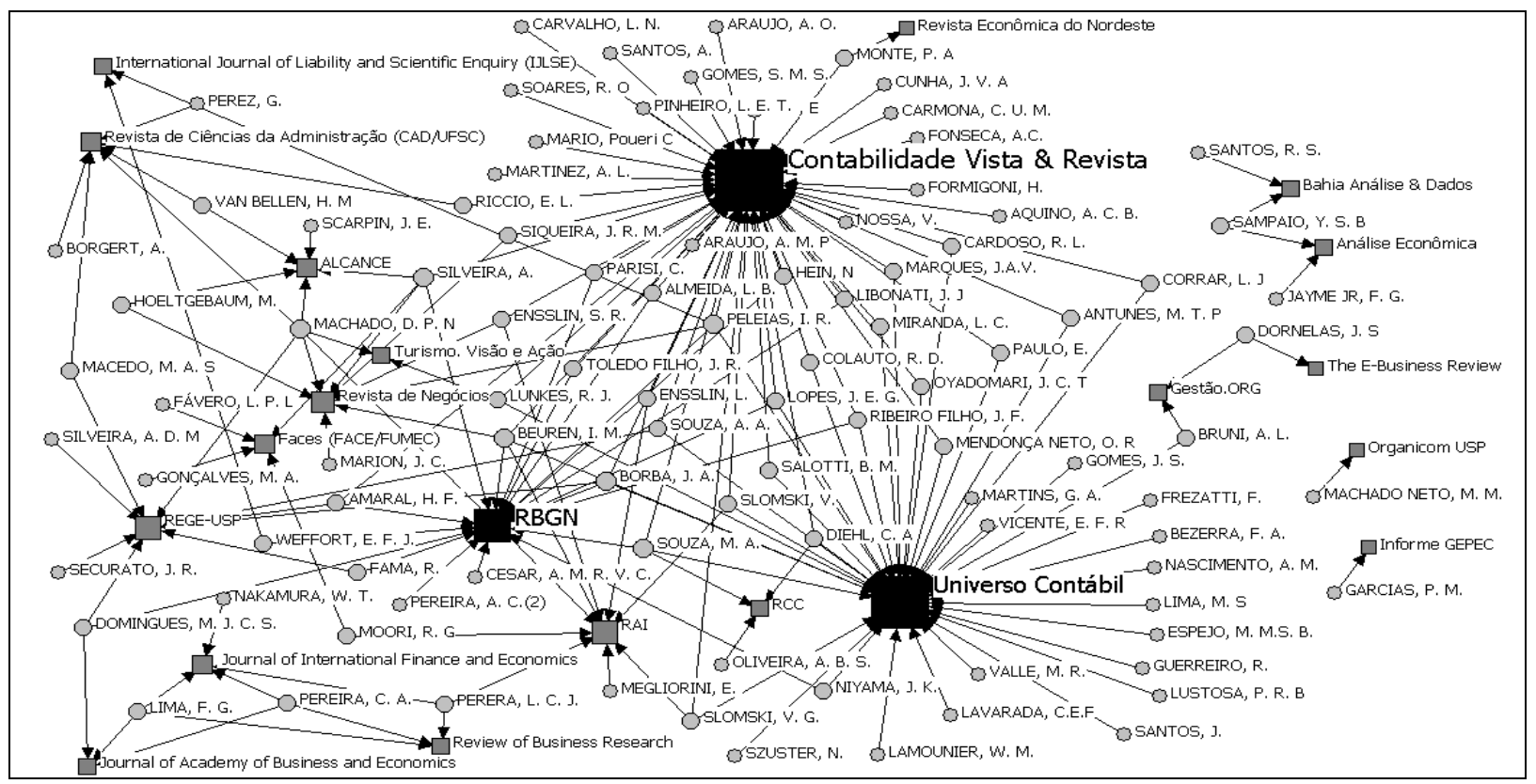

Figura 4. Redes sociais das publicações nos periódicos classificados como B3.

Nota. Fonte: dados da pesquisa.

Observa-se na Figura 4 que a posição central da rede social é ocupada pela Contabilidade Vista \& Revista, que se configura como um periódico com publicações trimestrais e uma média de seis artigos por edição. Na sequência está o periódico Universo Contábil, cuja periodicidade de publicação era quadrimestral e a partir de 2008 tornou-se trimestral; em média são publicados 5 artigos na secção nacional e 4 artigos na secção internacional. Ocupando a terceira posição está a Revista Brasileira de Gestão de Negócios (RBGN), com publicações trimestrais e uma média de seis artigos por edição.

Dos 38 periódicos que compõem este estrato do Qualis CAPES, a rede social compõe-se de 16 periódicos nacionais e 5 internacionais, demonstrando assim a existência de lacunas estruturais no estrato. A maioria desses periódicos publica artigos que abordam temas de natureza contábil. No triênio 2007-2009, a maioria dos periódicos da área contábil encontrava-se classificada no estrato 3 da CAPES. Este aspecto favorece a formação de redes sociais entre os atores, por publicarem sua produção científica em uma menor dispersão de periódicos sob o ponto de vista temático, permitindo aos atores conhecer as publicações um dos outros em um mesmo periódico ou em uma quantidade reduzida de periódicos. 


\section{Periódicos classificados como B4 e B5}

Na Figura 5 apresentam-se as redes sociais formadas a partir das publicações nos periódicos classificados no Qualis CAPES como B4, com pontuação correspondente a 20 pontos, e os B5, com pontuação equivalente a 10 pontos.

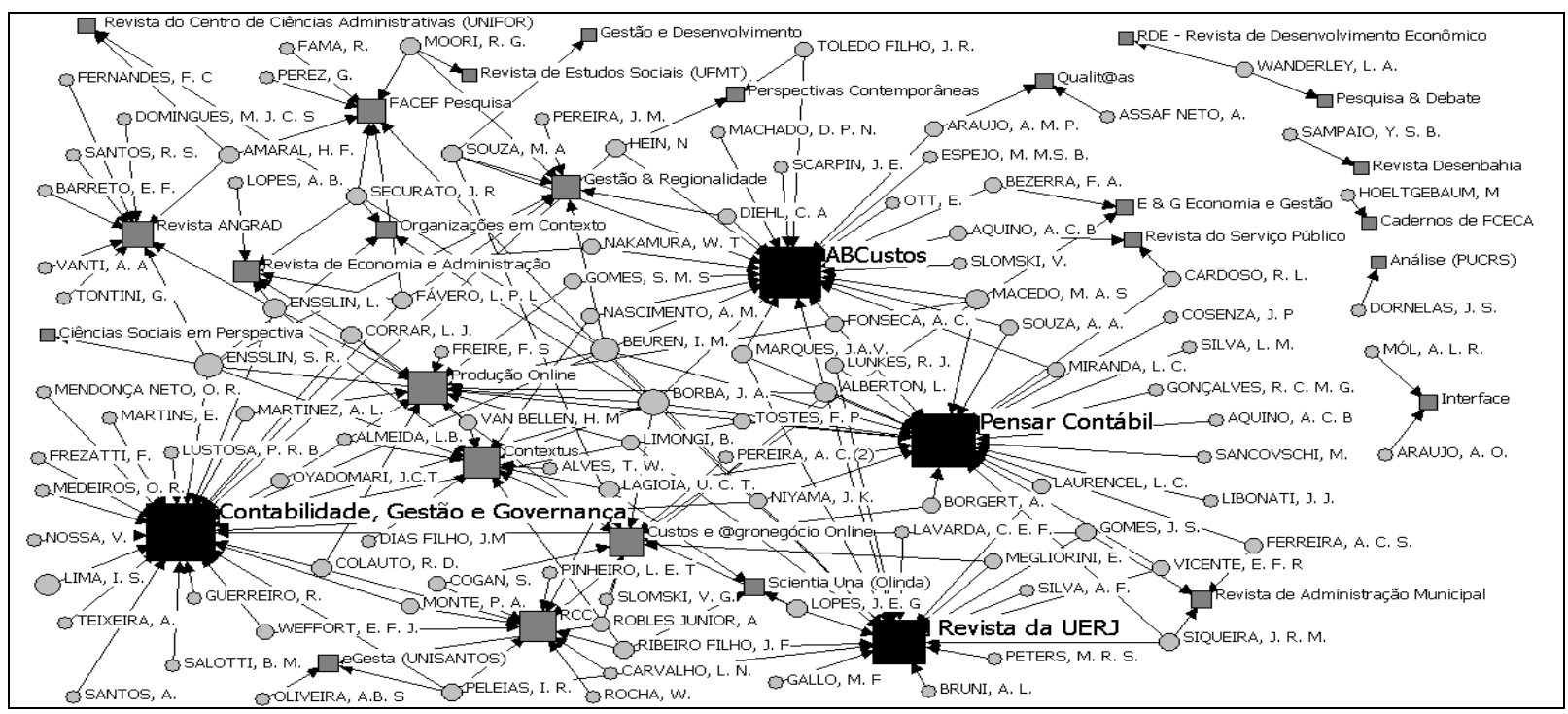

Figura 5. Redes sociais das publicações nos periódicos classificados como B4 e B5

Nota. Fonte: dados da pesquisa.

Na Figura 5 observa-se que a centralidade é ocupada por dois periódicos, Pensar Contábil e Contabilidade, Gestão e Governança. Na segunda e terceira posição constam a Revista ABCustos e a Revista de Contabilidade do Mestrado em Ciências Contábeis da UERJ respectivamente. Em consonância com os outros estratos analisados, percebe-se a presença de lacunas estruturais, pois dos 34 periódicos que compõem o estrato B4 e dos 36 que compõem o estrato B5, apenas 26 periódicos participam desta rede social, sendo dois internacionais.

Infere-se que a presença das lacunas estruturais nas redes sociais formadas pela produção científica definitiva dos programas de pós-graduação em ciências contábeis está presente em todas as estratificações do Qualis CAPES no triênio 2007-2009. Esses resultados se coadunam com os achados de Nascimento et al. (2009), que elucidam esta questão ao comentar a existência de um gap no número de publicações em periódicos. Os autores sugerem que este gap seja preenchido pelos egressos do doutorado em ciências contábeis da FEA/USP, considerando-a tarefa imprescindível, já que os periódicos se caracterizam como forma de veiculação das pesquisas mais acessível à sociedade.

\section{Redes sociais formadas pelos programas de pós-graduação em ciências contábeis}

Na Figura 6 evidenciam-se as redes sociais formadas a partir da produção científica definitiva dos docentes pertencentes aos programas de pós-graduação analisados. 


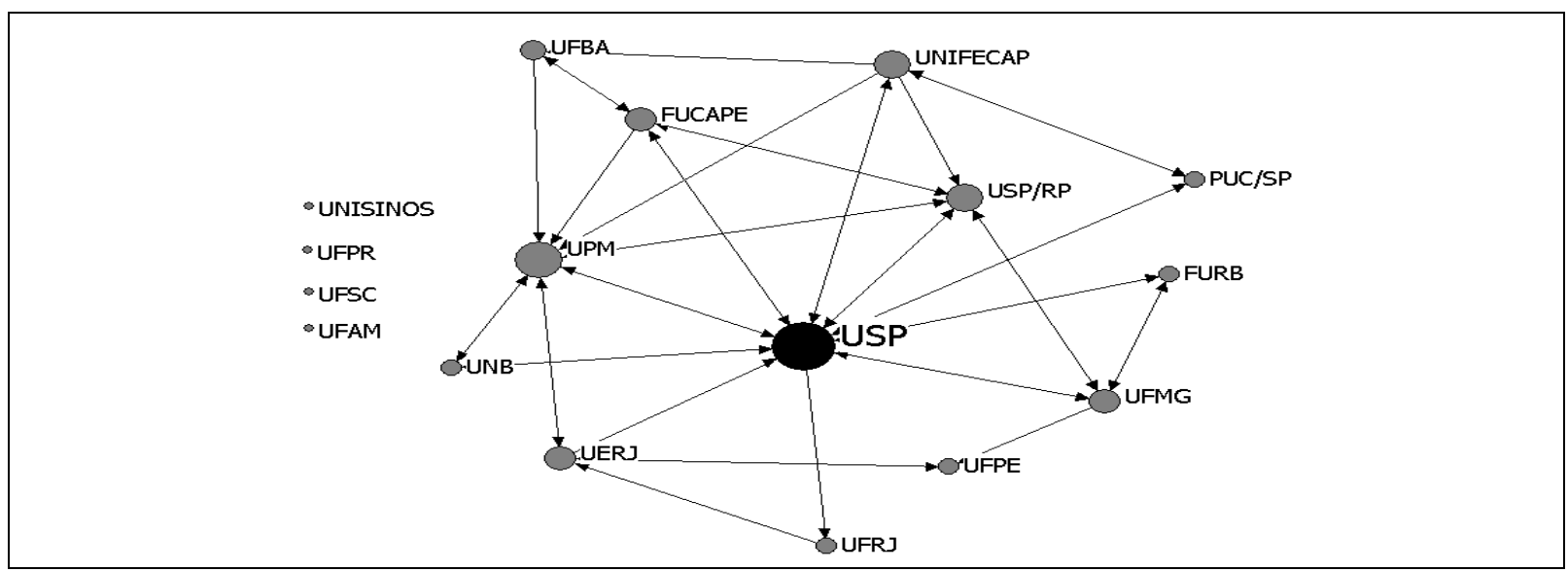

Figura 6. Redes sociais formadas pelos programas de pós-graduação em ciências contábeis.

Nota. Fonte: dados da pesquisa.

Na Figura 6 observa-se que a posição central da rede formada a partir da produção científica definitiva dos 21 cursos de pós-graduação em ciências contábeis é ocupada pela Universidade de São Paulo (USP). Percebe-se também a criação de um grupo interligado composto por 13 Instituições de Ensino Superior. Por outro lado, nota-se a presença de uma lacuna estrutural caracterizada pela Unisinos, UFPR, UFSC e UFAM, que não estabelecem relações com o grupo. A Tabela 4 demonstra as relações sociais estabelecidas pelos programas analisados.

Tabela 4

Laços dos Programas de Pós-Graduação em Ciências Contábeis da Rede de Colaboração

\begin{tabular}{lcc}
\hline \multicolumn{1}{c}{ Programa de Pós-Graduação (Atores) } & Laços & Percentual \\
\hline USP - Universidade de São Paulo & 34 & $23,6 \%$ \\
UPM - Universidade Presbiteriana Mackenzie & 22 & $15,3 \%$ \\
USP-RP - Universidade de São Paulo - Campus Ribeirão Preto & 21 & $14,6 \%$ \\
UFMG - Universidade Federal de Minas Gerais & 12 & $8,3 \%$ \\
FUCAPE - Fundação Instituto Capixaba de Pesquisa em Contabilidade & 11 & $7,6 \%$ \\
UNIFECAP - Fundação Escola de Comércio Álvares Penteado & 11 & $7,6 \%$ \\
FURB - Universidade Regional de Blumenau & 8 & $5,6 \%$ \\
PUC-SP - Pontifícia Universidade Católica de São Paulo & 7 & $4,9 \%$ \\
UFBA - Universidade Federal da Bahia & 5 & $3,5 \%$ \\
UNB - Universidade de Brasília & 5 & $3,5 \%$ \\
UERJ - Universidade do Estado do Rio de Janeiro & 4 & $2,8 \%$ \\
UFRJ - Universidade Federal do Rio de Janeiro & 2 & $1,4 \%$ \\
UFPE - Universidade Federal de Pernambuco & 2 & $1,4 \%$ \\
Universidade Federal de Santa Catarina (UFSC); Universidade Federal do & 0 & $0,0 \%$ \\
Paraná (UFPR); Universidade Federal da Amazônia (UFAM) e Universidade \\
do Vale do Rio dos Sinos (UNISINOS); & & \\
\hline
\end{tabular}

Nota. Fonte: dados da pesquisa.

Observa-se na Tabela 4 que a Universidade de São Paulo (USP), além de ocupar a centralidade da rede, estabeleceu também o maior número de ligações com os demais atores da rede social. Acredita-se que esta posição de liderança se deve ao fato de que esta instituição apresenta o primeiro e 
o mais prestigiado programa de pós-graduação na área, com um curso de mestrado e de doutorado na área de Contabilidade instalados na década de 1970 na cidade de São Paulo (Nascimento et al., 2009). Na sequência está a UPM, com $15,3 \%$ dos laços na rede social da produção científica definitiva, seguida pela USP-RP $(14,6 \%)$, UFMG $(8,3 \%)$, FUCAPE $(7,6 \%)$, UNIFECAP $(7,6 \%)$ e FURB $(5,6 \%)$ respectivamente.

Esses resultados corroboram os achados de Nascimento et al. (2009), quando destacam que há necessidade no fortalecimento das redes sociais estabelecidas entre os egressos do doutorado em ciências contábeis da FEA/USP. Essa necessidade decorre das lacunas estruturais existentes no relacionamento dos programas de pós-graduação; vários desses egressos da FEA/USP compõem o atual corpo docente dos programas de pós-graduação analisados. Está em consonância também com a pesquisa realizada por Guimarães et al. (2009) nos programas de pós-graduação em administração, que detectaram a presença das redes sociais fracas, esparsas e pouco densas entre os programas analisados.

\section{Conclusões}

O estudo objetivou identificar a formação de redes sociais na produção científica definitiva do triênio 2007-2009 dos programas de pós-graduação de ciências contábeis do Brasil. Pesquisa documental foi realizada por meio de um estudo bibliométrico e sociométrico, considerando os 199 docentes permanentes de 21 cursos de mestrado e doutorado dos programas de pós-graduação em ciências contábeis, distribuídos em 17 instituições de ensino superior. A coleta dos dados da produção científica definitiva - que compreendeu neste estudo os artigos publicados em periódicos e os artigos aceitos para publicação em periódicos - do triênio 2007-2009, publicada na Plataforma Lattes, foi realizada no período de 10 a 13 de agosto de 2009 e complementada no período de 2 a 4 de fevereiro 2010. Na análise dos dados utilizou-se estatística descritiva, com auxílio do software UNICET® 6 para a confecção das redes de cooperação entre os programas investigados.

Sobre a evolução da produção científica definitiva dos programas no triênio 2007-2009, os resultados da pesquisa mostram que o programa da Universidade de São Paulo de Ribeirão Preto (USP-RP) apresentou a maior evolução na produção científica definitiva no período analisado, 342,86\%; na segunda posição está o programa da Universidade do Estado do Rio de Janeiro (UERJ), com $100 \%$ de variação no triênio 2007-2009. Em seguida aparecem os programas da Universidade do Vale do Rio dos Sinos (UNISINOS) e Universidade Federal da Bahia (UFBA). De modo geral, observou-se que os programas com conceito 3 apresentaram maior crescimento em termos percentuais, o que pode denotar certa estabilidade dos programas com conceitos mais elevados, embora alguns destes tenham apresentado variação negativa no período.

No que concerne à veiculação da produção científica definitiva em periódicos, tendo como referência a classificação do Qualis CAPES, os que sobressaíram em cada extrato foram: (a) A1 e A2 do Qualis - a Brazilian Administration Review (BAR) e a Revista de Economia e Sociedade Rural; (b) B1 do Qualis - a Revista de Contabilidade \& Finanças (RC\&F), seguida da Revista de Administração Contemporânea (RAC) e da Revista de Administração de Empresas (RAE); (c) B2 do Qualis - a posição central foi ocupada pela Brazilian Business Review (BBR), seguida pela Revista de Administração da USP (RAUSP) e pela Revista Base; (d) B3 do Qualis - a centralidade da rede social foi ocupada pela Contabilidade Vista \& Revista e seguida pela Revista Universo Contábil e pela Revista Brasileira de Gestão de Negócios (RBGN); (e) B4 e B5 do Qualis - a centralidade foi ocupada pela Pensar Contábil e pela Contabilidade, Gestão e Governança; na segunda e terceira posição estão a Revista ABCustos e a Revista de Contabilidade do Mestrado em Ciências Contábeis da UERJ respectivamente. Denota-se que a produção científica definitiva veiculada em periódicos pelos docentes permanentes dos programas analisados se apresenta de forma dispersa nas estratificações do Qualis CAPES. 
Em se tratando das redes sociais promovidas entre os programas de pós-graduação em ciências contábeis do Brasil, a posição central coube à Universidade de São Paulo (USP), com 23,6 dos laços da rede social. É o programa com maior conceito na CAPES (conceito 5) e pioneiro na oferta dos cursos de mestrado e doutorado na área contábil. Por conseguinte, grande parte dos docentes dos demais programas é egresso deste programa, o que favorece a formação de redes sociais com seus orientadores de doutorado. Em seguida aparecem a UPM, com 15,3\% dos laços na rede social, a USPRP $(14,6 \%)$, a UFMG (8,3\%), a FUCAPE $(7,6 \%)$, a UNIFECAP $(7,6 \%)$ e a FURB $(5,6 \%)$ respectivamente. Depreende-se que as redes sociais formadas a partir da produção científica definitiva dos programas no triênio 2007-2009 se apresentam com predominância de laços fracos, além da presença de lacunas estruturais em todas as estratificações do Qualis CAPES.

Estes achados se coadunam com os resultados da pesquisa de Guimarães et al. (2009), que constataram que as redes formadas pelos programas de pós-graduação em administração se apresentam com ligações fracas, esparsas e pouco densas. Na presente pesquisa, esta situação é reforçada com a presença de lacunas estruturais, presentes na rede social dos programas, principalmente dos programas da UFSC, UFAM, UNISINOS e UFPR que não se relacionaram com os demais atores da rede. Guimarães et al. (2009, p. 14) destacam que "estes resultados podem ser explicados por se tratar de área de conhecimento relativamente jovem no Brasil, em fase de consolidação e de institucionalização".

As conclusões do estudo devem ser consideradas dentro dos limites estabelecidos nas estratégias da pesquisa. Vale destacar que o estudo se limitou a analisar: (a) a produção científica definitiva dos artigos publicados e aceitos para publicação em periódicos, uma vez que a CAPES ainda não divulgou a tabela de pontuação para as produções científicas relativas a livros e capítulos de livros, que também se configuram como definitivas; (b) a produção científica definitiva dos docentes permanentes listados na página de cada programa, ou na sua ausência, informados pela secretaria do programa; (c) a produção científica definitiva dos artigos publicados e aceitos para publicação em periódicos relatados no $C V$ Lattes destes docentes permanentes; e, (d) o período que compreendeu o triênio 2007-2009. Recomenda-se para futuras pesquisas investigar a formação das redes sociais nos programas de pós-graduação em ciências contábeis quanto à intermediação (Betweenness), frequência de relacionamentos (DegreeVL) e centralidade de Bonacich (Power).

\section{Artigo recebido em 22.02.2010. Aprovado em 15.07.2010.}

\section{Referências}

Acedo, F. J., Barroso, C., Casanueva, C., \& Galán, J. L. (2006). Co-authorship in management and organizational studies: an empirical and network analysis. Journal of Management Studies, 43(5), 957-983.

Balestrin, A., Verschoore, J. R., \& Reyes, E., Jr. (2010). O campo de estudo sobre redes de cooperação interorganizacional no Brasil. Revista de Administração Contemporânea, 14(3), 458-477.

Burt, R. S. (1992), Structural holes: the social structure of competition. Cambridge: Harvard University Press.

Cervo, A. L., \& Bervian, P. A. (1996). Metodologia científica (4a ed.). São Paulo: Makron Books.

Coordenação de Aperfeiçoamento de Pessoal de Nível Superior. (2004). Portaria da CAPES $n^{o}$ 68/2004. Recuperado em 11 fevereiro, 2010, de http://www.uefs.br/ ppgbot/normas/parametros_areas_docentes_permanetes.pdf

Coordenação de Aperfeiçoamento de Pessoal de Nível Superior. (2009). Relação de cursos recomendados e reconhecidos. Recuperado em 8 agosto, 2009, de 
http://conteudoweb.capes.gov.br/conteudoweb/ProjetoRelacaoCursosServlet?acao=pesquisarIes $\&$ codigoArea $=60200006 \&$ descricaoArea $=$ CI\%CANCIAS + SOCIAIS + APLICADAS $+\&$ descrica oAreaConhecimento=ADMINISTRA $\% \mathrm{C} 7 \% \mathrm{C} 3 \mathrm{O} \&$ descricaoAreaAvaliacao $=\mathrm{ADMINISTRA} \%$ $\mathrm{C} 7 \% \mathrm{C} 3 \mathrm{O} \% 2 \mathrm{C}+\mathrm{CI} \% \mathrm{CANCIAS}+\mathrm{CONT} \% \mathrm{C} 1 \mathrm{BEIS}+\mathrm{E}+\mathrm{TURISMO}$

Coordenação de Aperfeiçoamento de Pessoal de Nível Superior. (2010). Avaliação do Qualis/CAPES. Recuperado em 11 fevereiro, 2010, de http://www.capes.gov.br/avaliacao/qualis

Cunha, J. V. A., Martins, G. A., \& Cornachione, E. B., Jr. (2008, setembro). Teses em ciências contábeis: uma análise de sua propagação. Anais do Encontro Nacional da Associação Nacional de Pós-Graduação e Pesquisa em Administração, Rio de Janeiro, RJ, Brasil, 32.

Espejo, M. M. S. B., Cruz, A. P. C., Walter, S. A., \& Gassner, F. P. (2009, junho). Campo de pesquisa em contabilidade: uma análise de redes sob a perspectiva institucional. Anais da Associação Nacional dos Programas de Pós-Graduação em Ciências Contábeis, São Paulo, SP, Brasil, 3.

Fonseca, V. S., \& Machado-da-Silva, C. L. (2002). Conversação entre abordagens da estratégia em organizações: escolha estratégica, cognicação e instituição. Organizações \& Sociedade, 9(25), 93-109.

Galaskiewcz, J., \& Wasserman, S. (1994). Advances in social network analysis: research in the social and behavioral sciences. London: Sage.

Granovetter, M. (1983). The strength of weak ties: a network theory revisited. Social Theory, 1, 201233. doi: $10.2307 / 202051$

Guimarães, T. A., Gomes, A. O., Odelius, C. C., Zancan, C., \& Corradi, A. A. (2009). A rede de programas de pós-graduação em administração no Brasil: análise de relações acadêmicas e atributos de programas. Revista de Administração Contemporânea, 13(4), 564-582. doi: 10.1590/S1415-65552009000400004

Hanneman, R., \& Ridlle, M. (2005). Introduction to social network methods. Riverside: University of California.

Larivière, V., Gingras, Y., \& Archambault, E. (2005). Comparative analysis of networks of collaboration of Canadian researches in the natural sciences, social sciences and the humanities. In P. Ingwerson \& B. Larsen (Eds.), Comptes rendus de la 10ième conference internationale de la international society for scientometrics and informetrics (ISSI) (pp. 565-574). Stockholm: Karolinksa University Press.

Macias-Chapula, C. A. (1998). O papel da informetria e da cienciometria e sua perspectiva nacional e internacional. Ciência da Informação, 27(2), 64-68.

Maciel, C. O. (2007). Práxis estratégicas e imersão social em uma rede de organizações religiosas. Dissertação de mestrado, Universidade Federal do Paraná, Curitiba, PR, Brasil.

Maia, M. F., \& Caregnato, S. E. (2008). Co-autoria como indicador de redes de colaboração científica. Perspectivas em Ciências da Informação, 13(2), 18-31.

Martins, G. A., \& Theóphilo, C. R. (2007). Metodologia da investigação científica para ciências sociais aplicadas. São Paulo: Atlas.

Martins, G. S. (2009). A construção do conhecimento científico no campo de gestão de operações no Brasil: uma análise sob a ótica de redes sociais do período 1997-2008. Dissertação de mestrado, Fundação Getúlio Vargas, São Paulo, SP, Brasil.

Miles, R., \& Snow, C. (1992). Causes of failure in network organizations. California Management Review, 34(4), 53. 
Nascimento, S., Santos, V., Rengel, S., \& Beuren, I. M. (2009, novembro). Análise das redes de pesquisa entre os egressos do curso de doutorado em ciências contábeis da FEA/USP. Anais do Encontro de Ensino e Pesquisa em Administração e Contabilidade, Curitiba, PR, Brasil, 2.

Nohria, N. (1992). Introduction: is a network perspective a useful way of studying organization in networks and organisations. In N. Nohria \& R. G. Eccles (Eds.), Networks and organizations: structure, form, and action (pp. 1-22). Boston, MA: Harvard Business School Press.

Nooteboom, B., Hans, B., \& Niels, G. N. (1997). Effects of trust and governance on relational risk. Academy of Management Journal, 40(2), 308-338

Olmeda-Gómez, C., Perianes-Rodriguez, A., Ovalle-Perandones, M. A., Guerrero-Bote, V. P., \& Anegón, F. M. (2009). Visualization of scientific co-authorship in Spanish universities: from regionalization to internationalization. Aslib Proceedings: New Information Perspectives, 61(1), 83-100.

Silva, A. B. O., Matheus, R. F., Parreiras, F. S., \& Parreiras, T. A. S. (2006). Análise de redes sociais como metodologia de apoio para a discussão da interdisciplinaridade na ciência da informação. Ciência da Informação, 35(1), 72-93.

Uzzi, B. (1997). Social structure and competition in interfirm networks: the paradox of Embeddedness. Administrative Science Quarterly, 42(1), 35-67.

Walter, S. A., Cruz, A. P. C., Espejo, M. M. S. B., \& Gassner, F. P. (2009, julho). Uma análise da evolução do campo de ensino e pesquisa em contabilidade sob a perspectiva de redes. Anais do Congresso de Controladoria e Contabilidade da USP, São Paulo, SP, Brasil, 9.

Wasserman, S., \& Faust, K. (1994). Social network analysis: methods and applications. Cambridge: Cambridge University Press. 